\title{
ReAlizing CEAB Graduate AtTributes USING THE CASE METHOD
}

\author{
David Effa, Steve Lambert, and Oscar Nespoli \\ Waterloo Cases in Design Engineering \\ University of Waterloo, Waterloo, Ontario, Canada
}

\begin{abstract}
The University of Waterloo (UW) offers seven fully accredited and internationally competitive engineering undergraduate programs. It has the largest undergraduate co-operative education program in the world, and the largest Engineering program in Canada. All UW engineering departments are refining and evaluating their undergraduate curricula in order to address the new Canadian Engineering Accreditation Board (CEAB) requirements, with its focus on learning outcomes and graduate attributes. This new perspective provides an opportunity for alternative pedagogical approaches for developing and assessing graduate attributes.
\end{abstract}

Over the past several years, the Waterloo Cases in Design Engineering (WCDE) group at UW has been developing and promoting the use of engineering design cases throughout the curriculum. These cases are developed primarily from our own students' work term experience. Cases provide an effective pedagogical method to integrate students' technical knowledge as well as develop appropriate engineering skills. Engineering cases help students understand and better appreciate the complexity of engineering practice, and gain valuable experience in engineering problem solving and working in teams. They naturally complement the real-world work experience they get on their co-op terms.

The primary objective of this paper is to present the use of case studies to promote active learning and assessment of engineering design with a focus on the CEAB graduate attributes. Some case studies have been developed to focus on specific $\mathrm{CEAB}$ attributes. An example case study will be presented, its implementation discussed, and the effectiveness of achieving the targeted learning outcomes will be discussed.

Keywords: CEAB graduate attributes; Case method; Design case study; Design education 